\title{
HERBERTO SALES: O ROMANCE E A BUSCA DE SI MESMO
}

Ângela Vilma S. Bispo Oliveira*

RESUMO: $O$ presente artigo pretende estudar o romancista baiano Herberto Sales nas relações que permeiam e entrecruzam vida e obra. Trata-se de estabelecer uma visão panorâmica da obra romanesca do escritor para, a partir daí, encontrarmos o autor nas particulares do sujeito biográfico; o memorialista, pois que sua obra ficcional traz cifrados rastros e vivências particulares em meio a memória de uma coletividade; e, principalmente, o prosador - homem que, na busca incansável de si mesmo, transforma o que viveu e o que poderia ter vivido em objeto estético.

PALAVRAS-CHAVE: Ficção, Memória, Autobiografia.

RESUMEN: Este texto pretende estudiar al novelista bahiano Herberto Sales, en las relaciones que atraviesan su vida y su obra. Se trata de estabelecer una vision panorámica de la obra novelística del escritor para, a partir de ese punto, encontrar al autor en las particularidades del sujeto biográfico; el memorialista, ya que su obra ficcional trae cifrados rastros y vivencias particulares aliadas a la memoria de una coletividad; y, principalmente, el prosador - hombre que, en busca incansable de si mismo, transforma lo que vivió y lo que podria haber vivido en objeto estético.

PALABRAS-CLAVE: Ficción, Memoria, Autobiografía.

*Mestre em Teoria da Literatura (UFPE)

Doutoranda em Teoria da Literatura (UFPE)

Foi no primeiro livro de memórias que Herberto Sales 
revelou o quão autobiográficas se faziam a sua relação com o conto, gênero no qual se firmou utilizando alguns dos instrumentos de romancista. Disse ele que para fazer um conto bastava-lhe "escrever um dos mil e um desimportantes episódios” com que ao longo do tempo vinha compondo a sua autobiografia, permitindo com que nelas tomassem parte as pessoas que conheceu e que recordava. ${ }^{1}$ Tal afirmação vem ilustrar as nítidas relações autobiográficas existentes na obra desse escritor - fato que nós já constatamos na sua contística, quando percebemos como o conto e o romance, assim como toda sua obra, estão entrelaçados, revelando a forte ligação às suas raízes e aos lugares em que viveu. ${ }^{2}$ É como prolongamento de estudo que podemos conjecturar o que abarca a obra desse romancista - sua vida, memória e arte literária se conjugam numa fronteira movediça e instigante.

Sabe-se o quanto as relações entre a biografia de um escritor e a narrativa curta se estreitam, haja vista as pulsações individuais que as cercam; nesse caso, lembramos também a poesia - formas idiossincráticas em que se denotam com mais evidência as relações de parentesco entre os acontecimentos existenciais e a literatura. Já o romance não nos permite, com muita evidência, tal afirmação, pois que a afluência de vias e percursos, aquela multiplicidade romanesca que possibilita várias histórias se entrelaçarem e personagens diversos se delinearem, nos põe num certo distanciamento da voz autoral, pessoal. O escritor como que se dissemina em diversidade de vozes e pessoas, desdobrando-se em muitos, em outros, em diversos, tornando quase que impossível encontrar sua fisionomia, aquela que costumamos chamar de biográfica. Nos labirintos do espelho - que é o romance - o escritor e sua imagem se transformam em fragmentos, onde por instantes pensamos vê-lo e o que detectamos são outros, ou quiçá ele mesmo, o autor, encarnado numa legião.

Herberto Sales sempre afirmou "escrever com sinceridade". Nas entrevistas, constantemente relatou as relações presentes entre seus livros e sua própria vida. Neles, fatos emergem como de um sonho: voláteis e presentes, os acontecimentos de sua existência permeiam a narrativa, seja ela romance, conto, ensaio e 
aquilo que, em falta de um outro nome, chamamos de literatura infanto-juvenil. Nessa vasta obra, caminhos e descaminhos do escritor se encontram, e o romancista é mesmo o bomem - naquilo que busca de possível unidade diante do múltiplo e indecifrável de sua condição; memorialista - pois que não consegue esquecer o seu passado, sua família, seus mortos; e, principalmente, é o prosador, porque transforma em material estético o que viveu, perseguindo a "verdade da alma" nos meandros feéricos daquilo que poderia ter sido e que não foi.

Tudo o que quero é ser realmente eu mesmo. Tenho de voltar de mim mesmo, para em mim mesmo ficar. ${ }^{3}$

Sou um habitante do passado, estrangeiro em terras do presente e do futuro. ${ }^{4}$

Literatura não é apenas o que é feito com arte literária. É, também, o que se faz com a verdade da alma. ${ }^{5}$

Nos restos perdidos de mim busco o outro que não fui e que não sou. ${ }^{6}$

"Um homem em busca de si mesmo, indisfarçável e puro", assim o definiu Austregésilo de Athayde, 7 quando da publicação da trilogia herbertiana de memórias. Depois de uma constante perseguição de si na obra ficcional, Herberto Sales resolve pôr termo em suas confissões, existenciais e factuais, nos três volumes memorialísticos de sua bibliografia. Neles, o homem assina deliberadamente a confissão, permeada muitas vezes da literariedade que a deixa suspensa e da verdade crua que a desestabiliza. $\mathrm{Na}$ obsessão pela sinceridade, mostra-se assim como é, e dele, do homem Herberto Sales, podemos endossar aquela definição que o mesmo fez a respeito de um outro escritor, amigo seu.

... Era um homem inteiro em suas duas metades: nas suas antipatias e nas suas simpatias. Um raro ser humano fiel a si mesmo nos seus extremos. Não brincava em serviço nos seus ódios. E dava plantão em sua gratidão. ${ }^{8}$ 
Como reiterou Cid Seixas, "Herberto xinga com raiva e beija com amor" e "não abraça quando brigar devia, pois que, "assim como o escritor, o homem não é invernizado por fora". Essa personalidade forte vai influenciar a divulgação da obra, explicando talvez o silêncio atual que desce sobre sua literatura e seu nome. O homem e o escritor pagam um preço "alto" por dizer "certas verdades", sendo legado, pela mídia e mercados editoriais, a um esquecimento que nos perturba, motivando-nos ao trabalho amoroso e justo de "dizê-lo", "contá-lo". Essa é uma reação natural do leitor que se encontra na memória do outro, na literatura que promove o reencontro "com o que temos em nós de mais profundo e verdadeiro", como bem assinalou Herberto, ${ }^{10}$ sendo que nela, na obra que lemos, "nos identificamos em nossas convicções mais profundas, em nossas dúvidas e inquietações". ${ }^{11}$ Assim, nessa relação crítica, que também permeia o autobiográfico, nos situamos como seres que se ficcionalizam, adentrando como personagens $\mathrm{da}$ narrativa que se encontra em permanente construção.

Como leitores, o escritor escolhido por nós se transforma num ser especial, pois que é muito difícil separar a obra, que nos identificamos, do autor que a escreveu. Estamos, quase todo o tempo, buscando a pessoa em meio a escrita; sabemos que o homem é o arquiteto dos vestígios, diluindo suas pegadas nas fronteiras, seja do sonho, seja da palavra materializada. Por mais que o autor tente se esconder entre as páginas, intuímos que sua história pessoal de alguma maneira se espraia e flui, evanescente ou cristalizada. Simulacro que encena a própria alteridade, ${ }^{12}$ a literatura aqui funciona como enigmática busca do autor. A variante da crítica como história policial, proposta pelo argentino Ricardo Piglia, situando o crítico como "decifrador de oráculos" e o escritor como "o delinqüente que apaga suas pegadas e cifra seus crimes", ${ }^{13}$ nos possibilitará a investigação de Herberto Sales, que, nas interfaces do romance, busca a si mesmo e se esconde. Sua presença persiste, não atrás do texto - como bem assinalou Roland Barthes - mas perdido no meio dele. ${ }^{14} \mathrm{~A}$ vida do autor 
torna-se a composição da ausência, rastro que não autentica sua passagem, tampouco legitima acontecimentos vividos, mas que, ao tempo em que flutua e se dissipa, permanece como uma sombra. E é essa sombra que perseguimos ao revisitarmos seus diários, documentos, entrevistas dadas, e, principalmente, em meio a seu romance. Perscrutando aquelas "verdades da alma" - enviesadas e perversas - que coabitam os enredos e artifícios literários, notamos que sua figura se impõe e a relação que temos com ela é tão espessa quanto a tentativa de totalizá-la. É assim que entramos no reino do romanesco, configurando as formas enigmáticas e múltiplas das leituras que empreendemos sobre o mundo.

Numa entrevista, ao ser questionado sobre a sua relação com o garimpo, projeto do primeiro livro (Cascalbo - 1944), e se o mesmo acreditava na feitura romanesca a partir de uma pesquisa deliberada ou, ao contrário, a partir de uma experiência natural, espontânea, de fatos vividos e assistidos, Herberto Sales afirmou que "cada pessoa que tem que escrever um romance", na verdade, de alguma maneira, ela "já traz dentro de si os romances que tinha de escrever”. Esses romances surgem a partir de circunstâncias que envolvem o escritor, configurando-se como uma "superposição, uma sedimentação de vivências". ${ }^{15}$ Explicando, com tal afirmação, a gênese de Cascalho, dela nos apropriamos para agregá-la à gênese de todos os seus outros romances, tão bem contados por ele na sua trilogia memorialística.

É imperioso dizermos aqui, mais uma vez, que a obra de Herberto Sales, em temas e formas, acompanhou seus percursos biográficos. De Cascalho (1944) a A Prostituta (1996) - último romance -, visualizamos aqueles caminhos por ele percorridos. Nascida de uma relação visceral com a vida, tal obra vem confirmar a posição do escritor diante de uma época, de sua existência e de sua criação literária. Nesta se insere, sim, o autor que a escreveu, munido de uma identidade particular, a despeito de tal identidade ser quase sempre - em sua narrativa, como em todas as narrativas - uma procura constante e, possivelmente, sem solução. Muito mais, nessa literatura se insere, sim, o homem, seus personagens são todos 
nós, impressos nos abismos da perplexidade e da mais compassiva ironia, pois que é a tessitura humana que a perpassa.

Pouco sabemos de nós - e vivemos. É o que nos sugerem as entrelinhas da prosa herbertiana, que, dizendo passado e presente, possibilita-nos visualizarmos os caminhos do homem, do prosador e do memorialista, confirmando a certeza de que a obra literária traz a vida do escritor, mas ultrapassa-a, vai além. Essa mobilidade do eu, que se mostra e se esconde, e que faz da biografia uma encenação é o que mais nos interessa. Aqui Herberto Sales dá a mão a Mnemosyne, a deusa da memória, e canta o que foi, mas também o que poderia ter sido. Ou melhor, o que poderá ainda acontecer. Nesse tríplice caminho, presente, passado e futuro se encontram eivados de possibilidades, iluminados pela ficção.

Encontrar Herberto Sales, o andaraiense que viveu e testemunhou uma época, e que buscou retratá-la num romance comprometido com a denúncia social, nas linhas e entrelinhas de Cascalho, livro de 1944, totalmente reescrito em 1951, torna-se tarefa instigante quando, debruçados sobre sua obra, percebemos nele já nítidos aqueles "sinais particulares" que irão marcar a sua diç̧ão literária - não obstante a tentativa de desaparecimento - a partir de romances tão aparentemente distintos entre si. Nesse livro, escrito quando o autor tinha 24 anos, vimos a história centrada na sua terra natal, Andaraí, na qual histórias de garimpos e garimpeiros são contadas a partir da motivação do autor em denunciar as mazelas ali presenciadas. $\mathrm{O}$ depoimento humano-social ganha realces de crônica regionalista, onde a denúncia perpassada pelas páginas, na voz de um narrador aparentemente distante, perfaz-se num tom não planfetário, permitindo assim que as desigualdades sociais ali expostas ganhem notoridade nas variadas perspectivas estabelecidas pelo narrador. $\mathrm{O}$ autor quer esconder-se e ao mesmo tempo dizer-se, pois que sua vida está lá, inscrita na mobilidade e no desaparecimento, em meio àquela vida de garimpeiros:

... Todos três estavam agora curvados sobre a pedra que Zé de Peixoto tinha na mão. Dizer da ansiedade, 
do alvoroço e do atordoamento deles, é impossível. (...). (grifo nosso) ${ }^{16}$

... Encontram-se como que encurralados no âmago da gruna - seres insignificantes ao lado das grandes rochas úmidas e escuras, sobre as quais vêem projetadas suas próprias sombras. (...). (grifo nosso) $)^{17}$

Em 1961, com a publicação de Além dos Marimbus, segundo romance, encontramos o mesmo e outro Herberto - vemos os seus "sinais particulares", porém a estrutura é distinta de Cascalho. Nesse romance, escrito sobre a exploração madeireira de sua terra, percebemos exacerbada a preocupação com a forma artística, já prenunciada em Cascalho. Se este se fazia nos moldes memorialísticos dos contadores de histórias nordestinos, Além dos Marimbus nasce de um rigor visual na forma, apesar de não abandonar o cerne memorialístico. Nesses dois livros, o autor está escondido na voz de um narrador aparentemente distante, "disfarçado" na terceira pessoa do discurso indireto livre.

Um desconhecido cruzava agora aquelas paragens: Jenner. De casaco e culote de brim cáqui, chapéu de abas largas, e coturnos, conservava-se atento à mata que se descortinava além dos marimbus. (...). ${ }^{18}$

$$
* * *
$$

... E nessa personagem central [Jenner] talvez haja também um pouco de mim, por conta das reminiscências $\mathrm{da}$ minha viagem às matas. (...). ${ }^{19}$

Com Dados Biográficos do Finado Marcelino (1965), é outro o narrador que se pronuncia. A partir desse livro ficamos mais próximos do escritor, do homem e do memorialista Herberto Sales. Com a pretensa finalidade de contar a vida e a morte de um tio com o qual conviveu na época de sua adolescência, quando de Andaraí se transportou para estudar em Salvador, o narrador, entabulado na primeira pessoa do discurso, se posiciona, delineando a sua própria memória biográfica. A riqueza do "disfarce”, e da 
possível confissão do escritor, vem confirmar o entrelaçamento desse romance com os anteriores e, também, com as obras que virão depois. Nesse amalgamar de existências, percebemos a reiteração temática, estilística, a migração de personagens, todo o diálogo possível que nos ajudará a compreender a obra, o homem, o escritor. Funcionando como um divisor de águas, Dados Biográficos do Finado Marcelino nos traz o Herberto citadino, mas enraizado ainda à terra, alvo de suas reminiscências e presença decisiva em sua formação humana.

Andava pelos treze anos quando conheci meu tio Marcelino: era a primeira vez que eu ia a Salvador. Três dias antes deixara Andaraí, minha terra natal, em companhia de um comprador de diamantes, o Sr. Gumercindo, velho amigo de meu pai. A viagem enchera-me o coração de alvoroço. Com tamanha alegria eu partira - e mamãe chorava tanto ao abraçarme! - que os abalos da separação logo se diluíram na idéia daquela experiência nova e fascinante: ia conhecer a Capital. (...). ${ }^{20}$

É, a seguir, com o intuito de fazer um romance sobre seus antepassados que o escritor inicia as primeiras anotações que irão desaguar num livro publicado oito anos após a idealização - Os Pareceres do Tempo (1984). É importante situá-lo aqui, cronologicamente, a fim de percebemos como a história pessoal de Herberto se posiciona diante do fazer literário - história de uma vida recorrendo aos enviesados caminhos da verossimilhança, naquilo que abarca como possibilidades desentranhadas. $\mathrm{Na}$ verdade, Os Pareceres do Tempo requeria algo maior de seu autor, e ficou à espreita da melhor oportunidade de urdidura. E antes disso acontecer, Herberto escreveu e publicou dois livros que bem dirão das circunstâncias por ele vividas nas épocas datadas: 1976 e 1983, respectivamente $O$ Fruto do Vosso Ventre e Einstein, O Minigênio. Ele, Herberto Sales, era diretor do Instituto Nacional do Livro e, por isso, vivenciador do burocratismo que desumaniza as relações 
entre os homens. Nas reuniões que participava, vivia a anotar tolices para compor os dois romances. O Dicionário das Idéias Feitas flaubertiano de alguma maneira está inscrito nessa crítica atroz que Herberto faz às instituições sociais e seu jargão tecnocrático. $\mathrm{E}$ aqui que o riso, tão presente nesse escritor-contista, começa a pulsar. Lembremos que em estudo anterior nosso, ${ }^{21}$ descobrimos que o contista Herberto Sales nasceu no intervalo após a publicação de Dados Biográficos do Finado Marcelino e antes da aparição de O Fruto do Vosso Ventre. No livro de contos, Histórias Ordinárias (1966), já começamos a visualizar a mordacidade dessa crítica social com os contos Conselho e Ordem de Pagamento. Contos que anunciaram os romances seguintes. Riso que desabrocha cruel e positivo, pois que somado à sátira e à piedade - humor intuindo uma ternura pela nossa triste e engraçada condição humana.

A publicação seguinte é mesmo Os Pareceres do Tempo. Romance que compõe, a partir de alusões, a genealógica história do autor, ao restituir, ficcionalmente, dois personagens de sua família, Policarpo Golfão e Liberata. Confidenciou ele no livro de memórias:

... O meu Policarpo só tem que ver é com o meu antepassado Policarpo. Assim mesmo em linhas gerais de origem. Porque, enquanto o meu antepassado gastou todo o dinheiro que tinha, apostando a alma no baralho, e para isso indo de canoa São Francisco abaixo São Francisco acima em busca de parceiros, o Policarpo do romance é o desbravador romântico de Cuia d'Água. (... $)^{22}$

Para fazer este "romance de família", Herberto foi em busca de uma linguagem antiga e criou um cronista com a aparência de um estilo oitocentista, situando a história no Brasil colonial. Afirmou o escritor que aqui "a História foi apenas um prego" onde pendurou o seu romance, ${ }^{23}$ sugerindo com tal declaração a intencionalidade visceral do escritor - o resgate de sua história pessoal, ainda que o romance se desvincule por si mesmo da intenção do autor e nos deixe ver e refletir a história nacional, 
através das complexas relações que determinaram nossa formação. Assim, as fronteiras entre o imaginário e o real, entre a história e a literatura estão vinculadas aos meandros da verossimilhança, aos desejos de representação, aliadas ao lirismo de um terceiro olho, que tudo vê:

Finalmente, ainda com o sol alto, entreviu Policarpo o acampamento, através da discreta folhagem dumas árvores. Havia uma clareira, onde os índios moviamse lentos e descuidados, entregues aos seus quefazeres índios deles: ralavam mandioca, com mandioca faziam cauim, que bebiam, e farinha, que comiam. Três índias entreteciam cipós sentadas, acalentando no regaço uns balainhos que iam nascendo. Um índio soprava uma flauta de bambu; da flauta escorria uma música triste, que ia pingando tristeza em tudo. Era uma cena tão pura e essencial, tão embebida na essencialidade das coisas, com a mata rodeando calada e toda em verdor os índios, que parecia um começo de mundo: um mundo começando com um sopro de flauta. ${ }^{24}$

Em 1986, com A Porta de Chifre, Herberto Sales traz de volta a crítica mordaz à sociedade robotizada, iniciada com os contos de Histórias Ordinárias e, principalmente, com O Fruto do Vosso Ventre, romance que ele intitulou como marco do seu "apocalipse particular". ${ }^{25}$ Disfarçado em "relato anticientífico", A Porta de Chifre nos mostra uma Amazônia devastada em virtude das irresponsabilidades humanas. $O$ futuro se instala com crueldade (a história é situada no ano de 2352, começando exatamente no dia do aniversário do autor, 21 de setembro) e o resultado é o pior possível. O Herberto cruel, "castigador", como bem o definiu Antonio Olinto, ${ }^{26}$ aqui é mordaz e, ao mesmo tempo, humano, terno, piedoso, com tão frágeis destinos.

Se o escritor, de 1988 a 1991, dá uma pausa nos romances a fim de escrever a trilogia memorialística, podemos encontrar, entre o primeiro livro de memórias, Subsidiário - Confissões, Memórias 
e Histórias (1988) e o segundo, Andanças por umas Lembranças (1991), um pequeno romance intitulado $\mathrm{Na}$ Relva da tua Lembrança (1988), escrito quase que paralelamente ao primeiro livro de memórias. Nesse romance, em tudo diferente dos anteriores, o escritor quebra com o classicismo de sua escritura, tentando, como ele mesmo afirmou, "captar na escrita não a forma, mas a emoção", ${ }^{27}$ desfazendo propositalmente de tudo o que sabia fazer e fazia:

Vírgulas, travessões, em geral toda a parafernália diacrítica, e também todo o material convencional de apoio escritural romanesco, os calços dos advérbios, os parafusos das conjunções, os andaimes marcadinhos da marcação das personagens, peguei tudo e joguei para o ar e no ar fiz desaparecer tudo, (...). ${ }^{28}$

Nesse romance, corrosivo e ao mesmo tempo lírico, a poesia se instala para "segurar a barra dos parricidas", ${ }^{29}$ filhos desnaturados que resolvem matar os pais a fim de se verem livres destas "inúteis" criaturas. Narrado em primeira pessoa, o narrador é um velho que presencia tais acontecimentos do mais fundo de sua solidão. Escrito quando o autor tanto refletia sobre a dor de envelhecer, $\mathrm{Na}$ Relva da tua Lembrança apresenta-se como uma doce e trágica alegoria dos destinos humanos. Nele, os vestígios do escritor são evidentes - cenas, palavras e concepções dialogam com obras anteriores, tornando-se nítida a sua voz, que já é outra e a mesma, encenação que nos desestabiliza à medida em que nos promove o encontro com o autor. O narrador inicia a história dizendo que o que ali vai contar "pouco importa saber em que lugar se passou", e no segundo parágrafo, situa-se sentado numa pedra, "na beira do rio" - já conhecida do leitor herbertiano - , pedra que virava navio infâncias afora:

A pedra onde eu costumava me sentar ficava num desses trechos de areia. Muitas vezes imaginava que ela era um barco ancorado ali, e que eu era o comandante do barco. Não estava mais em idade de imaginar coisas 
assim, ter esses pensamentos de menino. Mas o menino que a gente um dia foi não há meio de largar a gente: fica escondido na memória da gente, fundo e escuro poço sem fundo, onde ele, o menino que a gente foi, de vez em quando vem à tona e fica boiando, como uma flor. ${ }^{30}$

No livro infanto-juvenil do autor, O menino perdido (1984), num capítulo intitulado "O castelo que virava navio", lá está a mesma pedra:

Fui direto ao areal, onde havia uma pedra muito grande, uma pedra enorme, que era o castelo de brinquedo do menino. (...)

Às vezes, a pedra deixava de ser um castelo. E virava um navio, que ia navegando no mar de areia, rompendo as ondas de areia. Ao leme ia o menino, comandante que fazia o seu navio apitar, apitando com um canudo de mamão. Sim. O menino costumava estar ali, no seu castelo ou no seu navio. Mas agora não estava. Tinha de procurá-lo em outro lugar. (...). ${ }^{31}$

Não obstante a localização afetiva, nostálgica, vimos, até aqui, que a preocupação localista inicial do escritor torna-se, com o decorrer de sua escritura, diluída, tendo Andaraí, terra natal, explicitamente ambientada nos dois primeiros romances, Cascalbo e Além dos Marimbus, se transformado, a partir daí, simbolicamente, no "mundo todo", adquirindo um teor universalizante. Herberto Sales deixou sua terra e fixou residência no Rio de Janeiro, em decorrência do sucesso que envolveu o primeiro romance. Foi assim que outros ambientes surgiram, seguindo a trajetória do escritor. As origens telúricas cederam lugar às preocupações com o homem citadino, emergindo a crítica às instituições sociais na figura caricata do ser robotizado e desumano, possuidor da linguagem uniforme. Porém, como já dissemos, detalhes de suas origens permanecem diluídos no cerne de sua literatura. Sentimos o quanto a terra continua presente em si, pois que faz parte de sua história pessoal, juntamente com o seu passado, sua família, 
seus mortos. Entretanto, estava faltando um regresso explícito a Andaraí - regresso intenso a si mesmo -, ocorrido no nono romance do escritor, Rio dos Morcegos (1993).

Tradução féerico-literária de uma cidade (Andaraí em tupiguarani significa, etimologicamente, rio dos morcegos), esse romance é uma busca proustiana do autor nos lugares que sonhou e viveu as duas fases mais intensas: a infância e a juventude. Andaraí surge feericamente iluminada pelas dolorosas perguntas de um adolescente que se debruça o tempo todo sobre si mesmo e o mundo, entranhado nas complexas perseguições de um sentido para a vida. Fatos emergem de uma neblina poética e, de quando em quando, o diálogo com Cascalho e outros livros, assim como com os três volumes de memórias do escritor, se avultam. Porém, aqui o que importa é outra coisa: não mais a denúncia social de Cascalho, pois que, em Rio dos Morcegos, Andaraí surge disfarçada naquele desdobramento sutil e invisível existente entre as fendas de uma cidade e o homem, e que envolve as nuanças psicológicas de deciframento do eu. Percebemos, assim, nesse romance, como uma biografia autoral se encena, se ficcionaliza, e os mistérios da vida e da morte são pontos que nos empurram à busca dos enigmáticos abismos de uma individualidade.

... Pedras do meu caminho. Por toda parte, inumeráveis e gerais, as pedras que me viram nascer, com os seus opacos olhos de pedra. O horizonte montanhoso, pedras bloqueando meus passos. A serra com os seus morros altos era um desafio, um enigma: muralha de rumos e ventos. Aonde ir? Que havia além da serra, minha prisão de pedras? Grandes pedras mudas me espreitavam: os gigantes de pedras dos meus medos infantis, das minhas incertezas de adolescentes. Pedras. $(\ldots)^{32}$

Essa busca de si prossegue ainda no penúltimo romance, Rebanho do Ódio (1995) livro-exorcismo, como o próprio autor proclama nas primeiras páginas, à maneira de uma indicação inicial 
para o leitor:

A quem me vai ler, quero aqui lembrar que uma vida longa (muito longa) faz sofrer a gente: os amigos vão morrendo, os afetos apodrecendo. De repente, só resta mesmo de cada um de nós a gente: nós sozinhos, somente nós, cercados de mágoas que magoam a gente. E então é preciso exorcizá-las, se queremos entrar de coração aliviado e limpo na eternidade.

A história se desenrola em São Pedro da Aldeia-(RJ) e se debruça sobre as complexas relações familiares, quando nelas estão envolvidas questões de fortuna e herança, ódio e mágoa. Entretanto, o livro poderia estar muito bem situado em Andaraí, ou, como disse o autor, em qualquer lugar, desde que nesse lugar o ódio assuma "uma forma diferente", "insinuando semelhança (ou identidade) entre uma impressão presente e uma lembrança aparentemente morta do passado". ${ }^{33}$ Percebemos que os fatos narrados, nesse romance, são pura ficção, mas os sentimentos que perpassam pelas páginas são fortes o suficiente para revelarem os desvãos biográficos de uma alma, ${ }^{34}$ as tristezas de um homem em perplexidade com a velhice, com o tempo e com as pessoas se desmascarando sem ilusões. ${ }^{35}$ Ficam, no ar e nas entrelinhas, a ressoar as palavras acima do escritor, confidenciando ao leitor sentimentos de sua história pessoal, de seu passado mais íntimo.

Com A Prostituta, em 1996, Herberto Sales se despede, deliberadamente, do romance. Esse livro é a história da prostituta Maria Corumba, remanescente criada pelo escritor, da família de $O s$ Corumbas, em homenagem ao romance de Amando Fontes que muito o impressionou, quando de sua leitura em Andaraí. Na verdade, a partir da criação do personagem, diz Herberto estar, muito mais, voltando à juventude, quando foi estudar em Salvador e ligou-se à boemia, em detrimento dos estudos. Nessa fase tão intensa, tinha o autor uma forte ligação com as prostitutas, e, resolvendo falar dessa fase, não poderia deixar de lado aquelas que ele denominou "irmãzinhas" e que fizeram parte de sua mocidade: 
A Prostituta sempre foi o livro que quis escrever. Quando era estudante, tive uma vivência enorme com prostitutas. Eu saía da pensão na quinta-feira e ficava dois, três dias na casa de uma delas. Era viciante, uma coisa extraordinária. Elas eram gente boa, maravilhosa, simples. (...) Eu queria falar da minha experiência como estudante e falar sobre mim sem elas não seria interessante.(...). ${ }^{36}$

Aliando vida e obra, mais uma vez, com esse livro Herberto Sales se despede do romance. Nas orelhas de $A$ Prostituta, no textoconfissão "O romancista, para as despedidas", o autor afirma ser esse livro, "de modo absoluto”, “a liberação de lembranças obscuras de sua vida, nas saudades machadeanas de si mesmo, numa hora em que em si mesmo se recolhe, invocando a misericórdia de Deus”. Nessa confissão, o autor se despede, deixando para nós, leitores, as interrogações do que foi e do que é uma vida, nas entrelinhas ficcionais do que aconteceu ou poderia ter acontecido - literatura como tentativa de fixar-se enquanto individualidade, somada ao enigmático sortilégio de poder também ser outro a fim de negar a đesintegração do ser, a morte. Não e a toa que o autor, nas páginas iniciais desse último romance, confessa a sua múltipla condição humana, situada entre as diversas "verdades da alma":

Sabe-se que cada homem é um ser múltiplo, e cada estado de alma seu é uma realidade à parte, sem perder no conjunto a sua totalidade anímica. Ou a sua unicidade intrínseca. Eu sou o mesmo romancista (a mesma alma) em cada um dos entre si tão diferentes romances que escrevi. 
${ }^{1}$ SALES, Herberto. Subsidiário - confissões, memórias e histórias, p. 491.

${ }^{2}$ VILMA, Ângela. A tessitura humana da palavra - Herberto Sales, Contista.

${ }^{3}$ SALES, Herberto. Op. Cit., p. 430.

${ }^{4}$ SALES, Herberto. Subsidiário 3 - Eu de mim, com cada um de mim, p. 307.

${ }^{5}$ Idem, p. 198.

${ }^{6}$ Idem, p. 274.

7 ATHAYDE, Austregésilo de. Herberto Sales, perfil de um homem. In: Subsidiário 3, p. 116.

${ }^{8}$ SALES, Herberto. Subsidiário 2 - Andanças por umas lembranças ., p. 218.

${ }^{9}$ SEIXAS, Cid. O riso da metralhadora. Do Cascalho ao Diamante. In: Triste Bahia, Oh QuãoDessemelhante, p. 117.

${ }^{10}$ SALES, Herberto. Subsidiário - Confissões, memórias e histórias p. 67. Assim definiu o "bom escritor": "O bom escritor é o que nos seus livros nos leva a um reencontro com o que temos em nós de mais profundo e verdadeiro".

${ }^{11}$ SALES, Herberto. Subsidiário 2, p. 139.

${ }^{12}$ ISER, Wolfgang. O fictício e o imaginário.

${ }^{13}$ PIGLIA, Ricardo. O laboratório do escritor, p. 72. 
${ }^{14}$ BARTHES, Roland. O prazer do texto, p. 38.

${ }^{15}$ SALES, Herberto. O depoimento. In: LEAL, Eneida. Eu, Herberto Sales, pp. 11-14

${ }^{16}$ SALES, Herberto. Cascalho, p. 116.

${ }^{17}$ Idem, p. 292.

${ }^{18}$ SALES, Herberto. Além dos marimbus, p. 8.

${ }^{19}$ SALES, Herberto. Subsidiário - confissões, memórias e histórias, p. 111.

${ }^{20}$ SALES, Herberto. Dados biográficos do finado Marcelino, p. 7.

${ }^{21}$ VILMA, Ângela. Op. Cit.

${ }^{22}$ SALES, Herberto. Subsidiário - Confissões, memórias e histórias, p. 391.

${ }^{23}$ Idem, p. 391.

${ }^{24}$ SALES, Herberto. Os pareceres do tempo, p. 365-366.

${ }^{25}$ SALES, Herberto. Subsidiário - confissões, memórias e histórias, p. 457.

${ }^{26}$ In: SALES, Herberto. Subsidiário 3 - Eu de mim com cada um de mim.

${ }^{27}$ SALES, Herberto. Subsidiário 2, Andanças por umas lembranças, p. 121.

${ }^{28} \mathrm{Idem}$. 
${ }^{29}$ Idem, p. 118.

${ }^{30}$ SALES, Herberto. Na relva da tua lembrança, p. 7-8.

${ }^{31}$ SALES, Herberto. O menino perdido, p. 11-13.

${ }^{32}$ SALES, Herberto. Rio dos morcegos, p. 27.

${ }^{33}$ SALES, Herberto. Rebanho do ódio. Palavras do autor impressas nas páginas iniciais do romance, à maneira de pórtico.

${ }^{34}$ GUIMARÃES, Márcia. Herberto Sales: O ódio sob a ótica amarga. In: A Tarde Cultural, 30-09-95.

35 SALES, Herberto. Subsidiário - confissões, memórias e histórias, p. 290. Afirmou desconsoladamente o autor: “(...) Estou envelhecendo. E a velhice é feita de desilusões. De desilusões filosóficas, que levam à descoberta da verdade humana. Ou da verdade sem ilusões.”

${ }^{36}$ SALES, Herberto. Entrevista concedida a Marielson Carvalho. A Tarde Cultural. Salvador, 20-09-1997.

\section{REFERÊNCIAS}

BARTHES, Roland. O prazer do texto. São Paulo: Perspectiva, 1999.

CARVALHO, Marielson. Herberto Sales (entrevista). In: A Tarde Cultural. Salvador, 20-09-1997.

GUIMARÃES, Márcia. Herberto Sales - O ódio sob a ótica amarga. Sobre as salinas do litoral fluminense, uma história de herança, intriga e solidão. In: A Tarde Cultural. Salvador, 30-09- 
1995.

ISER, Wolfgang. O fictício e o imaginário. Perspectivas de uma antropologia literária. Rio de Janeiro: EdUERJ, 1996.

PIGLIA, Ricardo. O laboratório do escritor. São Paulo: Iluminuras, 1994.

SALES, Herberto. Além dos marimbus. São Paulo: Círculo do Livro, s/d.

. Cascalho. São Paulo: Círculo do Livro, s/d.

. Dados biográficos do finado Marcelino. Rio de Janeiro: Civilização Brasileira, 1974.

. Eu, Herberto Sales - Entrevista concedida a Eneida Leal. Rio de Janeiro: Cátedra, 1978.

- Na relva da tua lembrança. Rio de Janeiro: Rocco, 1988.

. O menino perdido. São Paulo: Cia Editora Nacional, 1984.

. Os pareceres do tempo (Edição revista pelo autor). Rio de Janeiro: Civilização Brasileira, 1997.

. Rebanho do Ódio. Rio de Janeiro: Civilização Brasileira, 1995. 